\title{
A comparative evaluation of the performance of commercially available rapid immunochromatographic tests for the diagnosis of visceral leishmaniasis in Bangladesh
}

\author{
Prakash Ghosh¹, Md Golam Hasnain', Debashis Ghosh², Faria Hossain', James Baker', Marleen Boelaert', \\ Suman Rijal ${ }^{4}$ and Dinesh Mondal ${ }^{*}$
}

\begin{abstract}
Background: Accurate and early diagnosis of Visceral Leishmaniasis $(\mathrm{VL})$ is a prerequisite for proper treatment and restricting disease propagation in enldemic foci. An rK39 antigen-based immunochromatographic test is now recommended for its diagnostic accuracy and operational feasibility at point of care. In endemic regions of Bangladesh, rK39 or rKE16 antigen-based Rapid Diagnostic Tests (RDTs) are routinely performed on whole blood for diagnosis of VL. However, manufacturer's instructions require use of serum. Therefore, we wanted to assess whether the diagnostic accuracy of these RDTs is as good on whole blood as on serum.

Methods: We evaluated and compared the sensitivity and specificity of five different commercially available RDTs on whole blood and on serum. We enrolled $30 \mathrm{VL}$ patients, 35 endemic healthy controls and 30 Tuberculosis (TB) patients in our study from Mymensingh, a hyper-endemic region in Bangladesh.

Results: The sensitivity of all RDTs ranged between $96.67 \%$ (95 \% Cl: 82.72-99.44 \%) and $100 \%$ (95 \% Cl: 96.34-100 \%). The specificity ranged between $93.85 \%$ (95 \% Cl: 84.97-98.26\%) and $98.46 \%$ (95 \% Cl: 91.69-99.74 \%), except for the Onsite leishmania Ab (Rev B) kit which showed markedly lower specificity (31.25-58.46 \%). There was no significant difference in sensitivity and specificity between blood and serum. The Cohen kappa index ( $>0.97)$ indicated excellent agreement.

Conclusions: We conclude from the study that the use of blood for RDT in lieu of serum is appropriate for diagnosis of $V L$ in peripheral endemic regions provided the manufacturer recommendations are followed and the RDT is of good quality.
\end{abstract}

Keywords: Immunochromatographic test, Diagnosis, Visceral leishmaniasis, Bangladesh

\section{Background}

Visceral leishmaniasis or kala-azar is a systemic infection by an obligate intra-cellular parasite, and clinically manifests as chronic fever, fatigue, weakness, loss of appetite and weight loss. Hepatosplenomegaly, anemia, thrombocytopenia and leucopenia are the most common signs. If left untreated, the disease is

\footnotetext{
* Correspondence: din63d@icddrb.org

${ }^{1}$ Center for Nutrition and Food Security, International Center for Diarrheal

Disease Research, Bangladesh, Dhaka, Bangladesh

Full list of author information is available at the end of the article
}

fatal [1]. The disease is vector-borne, and is povertyrelated. In the Indian subcontinent it is caused by Leishmania donovani. In Bangladesh, people from 45 out of 64 districts face a potential risk of this fatal disease [2]. Although effective therapies to treat VL are available now, they are potentially toxic and are costly [3]. So, accurate diagnosis before treatment is imperative. In addition to that, visceral leishmaniasis is anthroponotic in the Indian subcontinent and no potential vaccine has been developed against VL till date. So, apart from vector control, early case 
detection and treatment are essential to restrict disease propagation $[3,4]$.

Demonstration of the amastigote parasite from spleen aspirates is considered as a gold standard for kala-azar diagnosis for its high sensitivity and specificity. However, spleen aspiration is an invasive method and requires a wellequipped clinical setting to perform [1]. Aspirates from bone marrow and lymph glands are associated with less risk but their sensitivities are not up to the mark [5]. Besides that, several serological and molecular techniques are available for diagnosis of VL [6]. Molecular methods require reference laboratory settings and are not appropriate for firstline health services. Several serological techniques including IFAT, ELISA and DAT have been developed, of which the DAT is most commonly used in field settings for its ease of execution. However, DAT requires multiple pipetting, is time consuming to perform, and its reading requires proper training $[6,7]$. Immunochromatographic tests (ICT) are rapid, reliable, simple and feasible to use at point of care, and have been recommended for use in first-line health centres in combination with a clinical case definition [8]. The currently available ICTs are based on rK39 and rKE16 antigen and most of them have to be used on serum samples [9]. The latter is again a constraint for use in a first-line health facility with a very basic laboratory.

According to the Bangladeshi national guideline, an rK39 Rapid Diagnostic Test (RDT) is recommended for VL diagnosis [10]. Notwithstanding manufacturer's instructions, this RDT is routinely performed on whole blood in peripheral endemic regions of Bangladesh [3]. In addition to that, rK39 dipstick tests have been performed throughout the kala-azar elimination program to do active surveillance and to detect cases early [11, 12]. Few reports have been published on the performance of available commercial RDTs on whole blood compared to serum [3,5]. It was therefore imperative to evaluate the diagnostic accuracy of the available commercial RDTs. So, the aim of our study was to study the agreement between results obtained in blood and in serum samples of five different types of RDTs; three based on rK39 and two on rKE16 antigen.

\section{Methods}

\section{Study site}

This study was conducted in two sites; the International Centre for Diarrheal Disease Research, Bangladesh (icddr,b) and the field site of parasitology laboratory, icddr,b at Muktagacha, Mymensigh. All participants of this study are permanent residents of Mymensingh, a hyper-endemic region in Bangladesh.

\section{Study population}

The included participants in this study were divided into three groups. The first group consisted of 30 active VL patients without past history of VL. For VL cases our inclusion criteria was either (a) parasitological confirmation or, (b) diagnosis of VL by National guideline along with complete clinical cure assessment after 6 months following treatment [13]. The second group consisted of 35 healthy controls who had no history of VL infection, were more than 18 years old and were negative in the DAT test (titre $<1: 1600$ ). The third group consisted of 30 TB patients with a positive sputum smear. Patients below 2 years old were excluded from the study.

\section{Sample collection, transportation and storage}

$4 \mathrm{ml}$ of blood was drawn from every confirmed VL patient, endemic healthy control and TB patient. Collected sample was divided into two parts and then one was transferred in an EDTA tube and other in an EDTA free tube for separation of serum. After 20-30 min, clotted blood was centrifuged at $2500 \mathrm{rpm}$ for ten min. at room temperature to separate serum. After that, RDT was performed using fresh blood and serum. The remaining blood and serum were stored at $-20{ }^{\circ} \mathrm{C}$ and transported frozen to the parasitology laboratory at icddr,b for repeating the tests .

\section{Test kits}

Five test kits were selected to perform RDT which fulfilled the operational criteria developed by the VL Laboratory Network. Among five test kits, four were received from two manufacturers, CTK Biotech (Onsite leishmania Ab; Rev A \& Rev B rapid test) and Span Diagnostics products (Signal-KA and Crystal-KA) and another from Inbios international Inc. (Kala-azar Detect). After arrival, test kits were unpacked and stored according to the manufacturers' instructions. Date of arrival, condition of test kits and product lot numbers were carefully recorded. RDT characteristics are listed in Table 1.

\section{Test procedure}

Prior to performing the test, RDTs were brought to room temperature and labeled with a random sample code. Each sample was tested with each of the 5 products according to manufacturer's instructions on serum and on blood. At first, a specific volume of sample was dispensed onto the RDT by micropipette and then chasing buffer was applied dropwise onto the RDT. The test result was interpreted and then recorded on a standardized form by two technicians at the minimum reading time and not more than $30 \mathrm{~min}$. The second technician was blinded to the first technician's reading. The presence of both a test and a control line was recorded as positive and the presence of only a control band was recorded as negative. The test result was recorded as invalid if the control band was found to be absent.

\section{Data analysis}

A database was generated in EPI-INFO for data storage and retrieving for further analysis. A double data entry 
Table 1 Characteristics of Rapid Diagnostic Tests (RDTs)

\begin{tabular}{|c|c|c|c|c|c|c|c|c|c|}
\hline Manufacturer & Product & Format & $\begin{array}{l}\text { Storage } \\
\text { Temp. }\end{array}$ & $\begin{array}{l}\text { Control } \\
\text { line }\end{array}$ & $\begin{array}{l}\text { Test } \\
\text { line }\end{array}$ & Sample volume $(\mu \mathrm{l})$ & $\begin{array}{l}\text { Buffer volume } \\
\text { (drops) }\end{array}$ & $\begin{array}{l}\text { Min. Reading } \\
\text { time (Minute) }\end{array}$ & $\begin{array}{l}\text { Max. Reading } \\
\text { time (Minute) }\end{array}$ \\
\hline \multirow{3}{*}{$\begin{array}{l}\text { Span diagnostic } \\
\text { Ltd. (Surat, India) }\end{array}$} & \multirow[t]{3}{*}{ Signal ${ }^{\oplus} K A$} & \multirow[t]{3}{*}{ Cassette } & \multirow[t]{3}{*}{$2-8^{\circ} \mathrm{C}$} & \multirow[t]{3}{*}{ Yes } & \multirow[t]{3}{*}{ rkE16 } & \multirow{3}{*}{$\begin{array}{l}20 \mu \mathrm{l} \text { of serum/blood } \\
\text { in } 80 \mu \mathrm{l} \text { of saline. } \\
50 \mu \mathrm{l} \text { of diluted } \\
\text { sample }\end{array}$} & Step 1:2 & \multirow[t]{3}{*}{2} & \multirow[t]{3}{*}{10} \\
\hline & & & & & & & Step 2:2 & & \\
\hline & & & & & & & Step $3: 3$ & & \\
\hline \multirow{2}{*}{$\begin{array}{l}\text { Span diagnostic } \\
\text { Ltd. (Surat, India) }\end{array}$} & \multirow[t]{2}{*}{ Crystal ${ }^{\oplus} \mathrm{KA}$} & \multirow[t]{2}{*}{ Dipstick } & \multirow[t]{2}{*}{$2-30^{\circ} \mathrm{C}$} & \multirow[t]{2}{*}{ Yes } & \multirow[t]{2}{*}{ rkE16 } & Blood $20 \mu \mathrm{l}$ & \multirow[t]{2}{*}{5} & \multirow[t]{2}{*}{15} & \multirow[t]{2}{*}{30} \\
\hline & & & & & & Serum $20 \mu \mathrm{l}$ & & & \\
\hline \multirow{2}{*}{$\begin{array}{l}\text { CTK Biotech. Inc } \\
\text { (San Diego, USA) }\end{array}$} & \multirow{2}{*}{$\begin{array}{l}\text { On site Leishmania } \\
\text { Ab (Rev A) rapid test }\end{array}$} & \multirow[t]{2}{*}{ Cassette } & \multirow[t]{2}{*}{$4-30^{\circ} \mathrm{C}$} & \multirow[t]{2}{*}{ Yes } & \multirow[t]{2}{*}{ rk39 } & Blood $40 \mu \mathrm{l}$ & \multirow[t]{2}{*}{1} & \multirow[t]{2}{*}{1} & \multirow[t]{2}{*}{15} \\
\hline & & & & & & Serum $30 \mu \mathrm{l}$ & & & \\
\hline \multirow{2}{*}{$\begin{array}{l}\text { CTK Biotech. Inc } \\
\text { (San Diego, USA) }\end{array}$} & \multirow{2}{*}{$\begin{array}{l}\text { On site Leishmania } \\
\text { Ab (Rev B) rapid test }\end{array}$} & \multirow[t]{2}{*}{ Cassette } & \multirow[t]{2}{*}{$4-30^{\circ} \mathrm{C}$} & \multirow[t]{2}{*}{ Yes } & \multirow[t]{2}{*}{ rk39 } & Blood $40 \mu \mathrm{l}$ & \multirow[t]{2}{*}{1} & \multirow[t]{2}{*}{1} & \multirow[t]{2}{*}{15} \\
\hline & & & & & & Serum $30 \mu \mathrm{l}$ & & & \\
\hline \multirow{2}{*}{$\begin{array}{l}\text { InBios international, } \\
\text { Inc (Seattle, USA) }\end{array}$} & \multirow[t]{2}{*}{ Kala azar Detect ${ }^{\mathrm{TM}}$} & Dipstick & $4-30^{\circ} \mathrm{C}$ & Yes & rk39 & Blood $20 \mu \mathrm{l}$ & 3 & 10 & 10 \\
\hline & & & & & & Serum $20 \mu \mathrm{l}$ & & & \\
\hline
\end{tabular}

procedure was followed for data entry. Data analysis was performed by SPSS software. The secured preservation of all source documents and electronic records was confirmed until the accomplishment of the study, data analysis and data dissemination. We calculated sensitivity and specificity with $95 \%$ CI using exact binomial methods for proportions. We used Cohen kappa index for agreement testing between test results. The values of Cohen $\kappa$ coefficients were interpreted according to Landis and Koch; 1.00-0.81: excellent, 0.80-0.61: good, 0.60-0.41: moderate, 0.40-0.21: weak and 0.20-0.00: negligible agreement [9].

\section{Ethical approval}

This study was approved by the icddr,b ethical review committee. Informed written consent was taken from each patient and control subjects or from the legal guardian for minor cases.

\section{Result}

\section{Participants' characteristics}

The average age was 38 in disease control group, 29 in healthy control group and in VL patient group it was 18 . The number of male and female participants was comparable among VL patients, while in disease control group the male-female ratio was 1:9 and in healthy control group it was 8:1. Average spleen size and duration of fever in VL patient group were $5.25 \mathrm{~cm}$ and 8 weeks respectively (Table 2).

\section{Diagnostic performance}

All RDTs showed excellent sensitivity and specificity (healthy and disease control) for fresh blood and fresh serum with only one exception Onsite leishmania Ab (Rev B) which showed low specificity. Sensitivity of all RDTs for fresh whole blood was found $100 \%$. For fresh serum, sensitivity was found $100 \%$ of four RDTs except signal KA $96.67 \%$. Specificity for fresh blood ranged from $58.46 \%$ to $98.46 \%$ and for fresh serum ranged from $55.38 \%$ to $98.46 \%$. All RDTs showed high sensitivity for stored blood except Rev A and Rev B (Table 3). For stored blood the sensitivity was found $100 \%$ for three RDTs except Rev A and Rev B. Sensitivity for stored serum was found $100 \%$ for four RDTs except kala-azar Detect ${ }^{\text {mix }}$ which showed a sensitivity of $96.77 \%$. Specificity for stored blood was found $98.46 \%$ except Onsite leishmania $\mathrm{Ab}$; Rev A and Onsite leishmania Ab; Rev B and for those tests were invalid. All RDTs gave excellent specificity for stored serum except Rev B. Specificity for stored serum ranged from $100 \%$ to $31.25 \%$ (Table 3 and 4 ). The high Cohen kappa index $(k>0.97)$ of four RDTs substantiated excellent agreement of test results between fresh whole blood and serum except Onsite leishmania Rev B which showed good agreement $(\mathrm{k}=0.69)$ between fresh whole blood and serum (Tables 5 and 6).

Table 2 Characteristics of the study subjects

\begin{tabular}{llll}
\hline Characteristics & VL patients & Healthy control & $\begin{array}{l}\text { Controls } \\
\text { with TB }\end{array}$ \\
& $n=30$ & $n=35$ & $n=30$ \\
\hline Age (Years) & $18.93 \pm 13.08$ & $29.09 \pm 8.18$ & $38 \pm 18.48$ \\
Mean $\pm S D$ & $16(53.3)$ & $0(0)$ & $3(11.11)$ \\
Children (<18 years), $n,(\%)$ & $14(46.7)$ & $35(100)$ & $27(88.89)$ \\
Adult (>18 years), $n,(\%)$ & & $31(88.6)$ & $17(56.7)$ \\
Sex & $17(56.7)$ & $4(11.4)$ & $13(43.3)$ \\
Male, $n$ (\%) & $13(43.3)$ & & - \\
Female, $n(\%)$ & & - & - \\
Spleen size (cm) & & & \\
Mean $\pm S D$ & $5.25 \pm 3.98$ & & \\
Duration of fever (Weeks) & $8.53 \pm 7.92$ & - & \\
Mean $\pm S D$ & & & \\
\hline Spleen size was measured through & & & \\
\hline
\end{tabular}

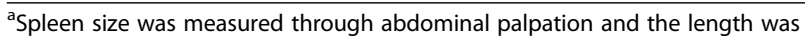
measured from the coastal margin along with its axis 
Table 3 Product test result (absolute number)

\begin{tabular}{|c|c|c|c|c|c|c|c|c|c|c|c|c|}
\hline \multirow[t]{4}{*}{ Product } & \multicolumn{12}{|l|}{ Case (30) } \\
\hline & \multicolumn{6}{|l|}{ Fresh } & \multicolumn{6}{|l|}{ Stored } \\
\hline & \multicolumn{3}{|l|}{ Blood } & \multicolumn{3}{|l|}{ Serum } & \multicolumn{3}{|l|}{ Blood } & \multicolumn{3}{|l|}{ Serum } \\
\hline & Positive & Negative & Invalid & Positive & Negative & Invalid & Positive & Negative & Invalid & Positive & Negative & Invalid \\
\hline Kalazar Detect ${ }^{\mathrm{TM}}$ & 30 & 00 & 00 & 30 & 00 & 00 & 30 & 00 & 00 & 30 & 00 & 00 \\
\hline Signal ${ }^{\circledR} K A$ & 30 & 00 & 00 & 29 & 01 & 00 & 30 & 00 & 00 & 30 & 00 & 00 \\
\hline Crystal ${ }^{\circledR} K A$ & 30 & 00 & 00 & 30 & 00 & 00 & 30 & 00 & 00 & 30 & 00 & 00 \\
\hline Onsite leishmania Ab (Rev A) & 30 & 00 & 00 & 30 & 00 & 00 & - & - & - & 30 & 00 & 00 \\
\hline Onsite leishmania Ab (Rev B) & 30 & 00 & 00 & 30 & 00 & 00 & - & - & - & 30 & 00 & 00 \\
\hline \multirow[t]{4}{*}{ Product } & \multicolumn{12}{|c|}{ Healthy Control (35) } \\
\hline & \multicolumn{6}{|l|}{ Fresh } & \multicolumn{6}{|l|}{ Stored } \\
\hline & \multicolumn{3}{|l|}{ Blood } & \multicolumn{3}{|l|}{ Serum } & \multicolumn{3}{|l|}{ Blood } & \multicolumn{3}{|l|}{ Serum } \\
\hline & Positive & Negative & Invalid & Positive & Negative & Invalid & Positive & Negative & Invalid & Positive & Negative & Invalid \\
\hline Kalazar Detect ${ }^{\mathrm{TM}}$ & 00 & 35 & 00 & 00 & 35 & 00 & 00 & 35 & 00 & 01 & 34 & 00 \\
\hline Signal ${ }^{\oplus} \mathrm{KA}$ & 00 & 34 & 01 & 00 & 35 & 00 & 01 & 34 & 00 & 00 & 35 & 00 \\
\hline Crystal ${ }^{\circledR} K A$ & 00 & 35 & 00 & 00 & 35 & 00 & 00 & 35 & 00 & 00 & 35 & 00 \\
\hline Onsite leishmania Ab (Rev A) & 01 & 34 & 00 & 02 & 33 & 00 & - & - & - & 00 & 35 & 00 \\
\hline Onsite leishmania Ab (Rev B) & 18 & 17 & 00 & 19 & 16 & 00 & - & - & - & 00 & 35 & 00 \\
\hline \multirow[t]{4}{*}{ Product } & \multicolumn{12}{|c|}{ Disease Control (30) } \\
\hline & \multicolumn{6}{|l|}{ Fresh } & \multicolumn{6}{|l|}{ Stored } \\
\hline & \multicolumn{3}{|l|}{ Blood } & \multicolumn{3}{|l|}{ Serum } & \multicolumn{3}{|l|}{ Blood } & \multicolumn{3}{|l|}{ Serum } \\
\hline & Positive & Negative & Invalid & Positive & Negative & Invalid & Positive & Negative & Invalid & Positive & Negative & Invalid \\
\hline Kalazar Detect ${ }^{\mathrm{TM}}$ & 02 & 28 & 00 & 02 & 28 & 00 & 01 & 29 & 00 & 01 & 28 & 01 \\
\hline Signal ${ }^{\oplus} K A$ & 02 & 28 & 00 & 02 & 28 & 00 & 01 & 25 & 04 & 01 & 28 & 01 \\
\hline Crystal ${ }^{\circledR} K A$ & 01 & 29 & 00 & 01 & 29 & 00 & 01 & 29 & 00 & 01 & 28 & 01 \\
\hline Onsite leishmania Ab (Rev A) & 02 & 28 & 00 & 02 & 28 & 00 & - & - & - & 03 & 26 & 01 \\
\hline Onsite leishmania Ab (Rev B) & 09 & 21 & 00 & 10 & 20 & 00 & - & - & - & 16 & 13 & 01 \\
\hline
\end{tabular}

\section{Discussion}

RDT is routinely performed on blood at primary health centers and district hospitals in endemic areas and it has been considered to be the first-line diagnostic tool for diagnosis of visceral leishmaniasis. This is the first study in Bangladesh which was conducted with a view to make a head to head comparison of the performance of five RDTs when performed on blood and serum. Though this study was not designed to estimate sensitivity and specificity, both rK39 and rKE16 based products except one brand showed excellent sensitivity and specificity for both fresh blood and serum. The sensitivity estimates are of course somehow optimistic, as 20 of the 35 cases were selected on the basis of an RDT according to national guidelines. More importantly, the operational feasibility of every RDT in primary health care was found to be up to the mark. Furthermore, the storing conditions for every RDT were easy to maintain in field settings except the Signal $\mathrm{K}$ which requires a storage temperature between $2{ }^{\circ} \mathrm{C}$ and $8{ }^{\circ} \mathrm{C}$. Inter-reader variability both in field setting and reference laboratory was minimal. The format (cassette or dipstick) of an RDT is an important factor for the performance of RDT, according to Rennie et al. [14]. In this study both formats performed equally well except Rev B and similar findings were reported by Kumar et al. [5].

In our study every valid test gave same result for blood and serum, and our results support the findings of Kumar et al. [5]. In a previous study disparity was found in several cases. In that study the parasitological status of patients was unknown and few cases gave positive result in RDT when performed on serum but negative on blood. The authors defined the disparity by low antibody titer in corresponding subjects with asymptomatic self-resolving infection [3].

In this study we evaluated five brands of RDT and found good results for fresh blood and serum except one brand. The Onsite Rev B gave lower specificity for both fresh and stored samples. In a previous study, the performance of Rev B was found to be poor in India as well as in Nepal [5]. In addition to Rev B, Rev A also gave invalid result for stored blood samples. According to manufacturer's 
Table 4 Specificity of different products

\begin{tabular}{|c|c|c|c|c|}
\hline \multirow[t]{3}{*}{ Product } & Fresh & Stored & & \\
\hline & Blood & Serum & Blood & Serum \\
\hline & \multicolumn{4}{|c|}{ Specificity (Healthy Control) } \\
\hline Kalazar Detect ${ }^{\mathrm{TM}}$ & $100(96.34-100)$ & $100(96.34-100)$ & $100(96.34-100)$ & $97.14(85.03-95.02)$ \\
\hline Signal ${ }^{\oplus} \mathrm{KA}$ & $100(89.52-100)$ & $100(89.90-100)$ & $100(96.34-100)$ & $100(89.90-100)$ \\
\hline Crystal ${ }^{\oplus K A}$ & $100(96.34-100)$ & $100(96.34-100)$ & $100(96.34-100)$ & $100(89.90-100)$ \\
\hline Onsite leishmania Ab (Rev A) & $97.14(85.03-99.52)$ & 94.29 (80.86-99.13) & - & $100(89.90-100)$ \\
\hline \multirow[t]{2}{*}{ Onsite leishmania Ab (Rev B) } & $48.57(31.39-66)$ & $45.71(28.84-63.45)$ & - & $20(8.48-36.95)$ \\
\hline & \multicolumn{4}{|c|}{ Specificity (Disease Control) } \\
\hline Kalazar Detect ${ }^{\mathrm{TM}}$ & 93.33 (77.89-98.99) & 93.33 (77.89-98.99) & 96.67 (82.72-99.44) & 96.55 (82.17-99.42) \\
\hline Signal ${ }^{\oplus} \mathrm{KA}$ & 93.33 (77.89-98.99) & 93.33 (77.89-98.99) & 96.15 (80.30-99.36) & $96.55(82.17-99.42)$ \\
\hline Crystal ${ }^{\oplus K A}$ & 96.67 (82.72-99.44) & 96.67 (82.72-99.44) & 96.67 (82.72-99.44) & $96.55(82.17-99.42)$ \\
\hline Onsite leishmania Ab (Rev A) & 93.33 (77.89-98.99) & 93.33 (77.89-98.99) & - & $89.66(72.62-97.69)$ \\
\hline \multirow[t]{2}{*}{ Onsite leishmania Ab (Rev B) } & $70(50.60-85.24)$ & $66.67(47.19-82.69)$ & - & $44.83(26.46-64.30)$ \\
\hline & \multicolumn{4}{|c|}{ Specificity (Healthy and Disease Controls combined) } \\
\hline Kalazar Detect ${ }^{\mathrm{TM}}$ & $96.92(89.30-99.54)$ & $96.92(89.30-99.54)$ & $98.46(91.69-99.74)$ & $96.88(89.14-99.53)$ \\
\hline Signal ${ }^{\oplus} \mathrm{KA}$ & 96.88 (89.14-99.53) & $96.92(89.30-99.54)$ & $98.36(91.17-99.73)$ & $98.44(91.57-99.74)$ \\
\hline Crystal ${ }^{\oplus} \mathrm{KA}$ & 98.46 (91.69-99.74) & $98.46(91.69-99.74)$ & $98.46(91.69-99.74)$ & $98.44(91.57-99.74)$ \\
\hline Onsite leishmania Ab (Rev A) & $95.38(87.08-98.98)$ & $93.85(84.97-98.26)$ & - & $95.31(86.89-98.97)$ \\
\hline Onsite leishmania Ab (Rev B) & $58.46(45.57-70.56)$ & $55.38(42.53-67.73)$ & - & $31.25(24.30-57.26)$ \\
\hline
\end{tabular}

instruction, Rev A and Rev B should not be performed on hemolysed blood. As blood stored without cryo-preserver gets hemolysed at freezing temperature. We can attribute this invalid result of Rev A and Rev B to storing procedure. In another multicenter study, RDTs from different companies were evaluated on archived serum samples from Indian subcontinent. Considering the high sensitivity and specificity of Crystal KA, Signal KA and Kala-azar detect, present study results are congruent to the findings of Cunningham et al. [9].

For specificity evaluation, RDT was done for endemic healthy controls and TB patients who were considered to be disease controls as VL shows cross-reactions with many

Table 5 Agreement between RDT result on blood versus serum in fresh and stored samples

\begin{tabular}{|c|c|c|}
\hline \multirow[t]{2}{*}{ Blood vs Serum $^{a}$} & \multicolumn{2}{|c|}{$\begin{array}{l}\text { Agreement index (Cohen's kappa) with } \\
95 \% \mathrm{Cl}\end{array}$} \\
\hline & Fresh & Stored \\
\hline Kalazar Detect $^{\mathrm{TM}}$ & 100 & $95.2(88.39-100)$ \\
\hline Signal ${ }^{\circledR} K A$ & $97.6(92.7-100)$ & 100 \\
\hline Crystal ${ }^{\otimes} K A$ & 100 & 100 \\
\hline Onsite leishmania Ab (Rev A) & $97.7(93.2-100)$ & - \\
\hline Onsite leishmania Ab (Rev B) & $69(54-84)$ & - \\
\hline
\end{tabular}

aWe didn't perform RDT on stored blood for Rev A and Rev B following manufacturer's instruction to avoid performing test on stored blood sample. That is why some kappa values are missing diseases, including trypanosomasis, malaria, tuberculosis, leprosy and amebiasis [6]. We found very few positive cases in the disease control group that can be attributed to potential serological cross-reactivity between Leishmania and Mycobacteria $[15,16]$.

\section{Conclusion}

All findings of this study infer the promising diagnostic accuracy of rK39 and rKE16 based RDTs except Rev B. As all RDTs did not perform equally on archived and fresh blood and serum samples, so manufacturers recommendations should be followed accordingly. In apart from several disparities, the quality performance and excellent agreement

Table 6 Agreement between RDT result on Fresh versus stored in blood and serum samples

\begin{tabular}{|c|c|c|}
\hline \multirow[t]{2}{*}{ Fresh vs Stored* } & \multicolumn{2}{|c|}{$\begin{array}{l}\text { Agreement index (Cohen's kappa) with } \\
95 \% \mathrm{Cl}\end{array}$} \\
\hline & Blood & Serum \\
\hline Kalazar Detect ${ }^{\mathrm{TM}}$ & $97.6(93-100)$ & $94.99(88.12-100)$ \\
\hline Signal ${ }^{\circledR} K A$ & $97.6(92.1-100)$ & $95.2(88.8-100)$ \\
\hline Crystal ${ }^{\circledR} K A$ & 100 & 100 \\
\hline Onsite leishmania $A b(\operatorname{Rev} A)$ & - & $88.4(78.5-98.3)$ \\
\hline Onsite leishmania $A b(\operatorname{Rev} B)$ & - & $12.7(0-35.6)$ \\
\hline
\end{tabular}

*We didn't perform RDT on stored blood for Rev A and Rev B following manufacturer's instruction to avoid performing test on stored blood sample. That is why some kappa values are missing 
substantiate the routine use of fresh blood instead of serum in dipstick test for diagnosis of visceral leishmaniasis in hyper endemic regions of Bangladesh providing RDT should be of good quality.

\section{Abbreviations}

RDT: Rapid diagnostic test; ELISA: Enzyme-linked immunosorbent assay; DAT: Direct agglutination test; VL: Visceral leishmaniasis; IFAT: Indirect fluorescence antibody test; Cl: Confidence interval.

\section{Competing interests}

The authors declare that they have no competing interests.

\section{Authors' contributions}

$P G, M G M, D G, F H, J B, M B, S R, D M$ : conceived and designed the study, analyzed the data and drafted the manuscript. PG, DG, FH, JB: performed the experiments and maintained the data source. $\mathrm{PG}, \mathrm{MGM}, \mathrm{MB}, \mathrm{SR}, \mathrm{DM}$ : performed the statistical analysis. All authors read and approved the final manuscript.

\section{Acknowledgement}

The authors would like to thank all the participants for their valuable participation into the research. The authors would also like to thank all the staff of the Kala Azar Research Team, Parasitology Laboratory, icddrb for their assistance in collection of the samples used in this evaluation. This work was supported by NIAID, NIH Grant Number: P50Al074321. The study was also supported by a grant from the Belgian Development Cooperation under the $3^{\text {rd }}$ Framework Agreement DGDC-ITM, Strategic Project "3.04 VL control".

\section{Author details}

${ }^{1}$ Center for Nutrition and Food Security, International Center for Diarrheal Disease Research, Bangladesh, Dhaka, Bangladesh. ${ }^{2}$ Center for Population Urbanization and Climate Change, International Center for Diarrheal Disease Research, Bangladesh, Dhaka, Bangladesh. ${ }^{3}$ Department of Public Health, Institute of Tropical Medicine, Antwrep, Belgium. ${ }^{4}$ Drugs for Neglected Diseases initiative, New Delhi, India.

Received: 13 November 2014 Accepted: 3 June 2015

Published online: 16 June 2015

\section{References}

1. Boelaert M, Bhattacharya S, Chappuis F, Safi SE, Hailu A, Mondal D, et al. Evaluation of Rapid Diagnostic Tests: Visceral Leishmaniasis. Nature Reviews Microbiology. 2007;5(11):S30-9.

2. Khan MG, Alam MS, Bhuiyan AT, Jamil MA, Saha B, Islam M, et al. (2011) Short communication: evaluation of a new rapid diagnostic test for quality assurance by kala azar elimination programme in Bangladesh. J Parasitol Res 2011:862475.

3. Matlashewski G, Das VNR, Pandey K, Singh D, Das S, Ghosh AK, et al. Diagnosis of Visceral Leishmaniasis in Bihar India: Comparison of the rK39 Rapid Diagnostic Test on Whole Blood Versus Serum. PLoS Negl Trop Dis. 2013;7(5):e2233.

4. Mbui J, Wasunna M, Balasegaram M, Laussermayer A, Juma R, Njenga SN, et al. Validation of Two Rapid Diagnostic Tests for Visceral Leishmaniasis in Kenya. PLoS Negl Trop Dis. 2013;7(9):e2441.

5. Kumar D, Khanal B, Tiwary P, Mudavath SL, Tiwary NK, Singh R, et al. (2014) A Comparative Evaluation of Blood versus Serum Samples in Rapid Immunochromatographic Tests for Visceral Leishmaniasis. J. Clin. Microbiol. JCM.01232-13.

6. Sundar S, Rai M. Lab Diagnosis Visceral Leishmaniasis. 2002;9(5):951-8.

7. Cota GF, de Sousa MR, Demarqui FN, Rabello A. The diagnostic accuracy of serologic and molecular methods for detecting visceral leishmaniasis in HIV infected patients: meta-analysis. PLoS Negl Trop Dis. 2012;6, e1665.

8. Chappuis F, Sundar S, Hailu A, Ghalib H, Rijal S, Peeling RW, et al. Visceral leishmaniasis: what are the needs for diagnosis, treatment and control? Nat Rev Microbiol. 2007;5(11):873-82.

9. Cunningham J, Hasker E, Das P, Safi SE, Goto H, Mondal D, et al. A Global Comparative Evaluation of Commercial Immunochromatographic Rapid Diagnostic Tests for Visceral Leishmaniasis. Clinical infectious diseases. 2012;55(10):1312-19.
10. The Use of Visceral Leishmaniasis Rapid Diagnostic Tests. TDR/WHO, 2008. doi: 10.2471/TDR.08.978-924-1597357

11. Ferdousi F, Alam MS, Hossain MS, Ma E, Itoh M, Mondal D, et al. Visceral leishmaniasis eradication is a reality: data from a community-based active surveillance in Bangladesh. Trop Med Health. 2012;40:133-9.

12. Gupta A, Nagar M, Mishra SS, Lahariya C. Visceral leishmaniasis (Kala Azar) elimination from Indian sub-continent by 2015. Int J Trop Dis Health. 2015;3(2):73-81.

13. Hasnain MG, Ghosh P, Baker J, Mondal D. An evaluation of the performance of direct agglutination test on filter paper blood sample for the diagnosis of visceral leishmaniasis. Am J Trop Med Hyg. 2014;91(2):342-4.

14. Rennie W, Phetsouvanh R, Lupisan S, Vanisaveth V, Hongvanthong B, Phompida S, et al. Minimising human error in malaria rapid diagnosis: clarity of written instructions and health worker performance. Trans R Soc Trop Med Hyg. 2007;101(1):9-18.

15. Pérez-Molina JA, Torres L, Ruiz MJ, Rivera M, Martí-Rabadán P, Bouza E. Lack of significant cross-reactivity between leishmania serology and mycobacteriosis in patients infected with HIV-1. Clin Microbiol Infect. 1999;5(5):253-5.

16. Hasnain MG, Ghosh P, Sonin MSIS, Baker J, Mondal D. First case of pulmonary tuberculosis and visceral leishmaniasis coinfection successfully treated with antituberculosis drug and liposomal amphotericin B. Clin Case Rep. 2014;2(6):331-2.

\section{Submit your next manuscript to BioMed Central and take full advantage of:}

- Convenient online submission

- Thorough peer review

- No space constraints or color figure charges

- Immediate publication on acceptance

- Inclusion in PubMed, CAS, Scopus and Google Scholar

- Research which is freely available for redistribution

Submit your manuscript at www.biomedcentral.com/submit
( BioMed Central 